Chirurgia (2021) 116: 700-717

No. 6, November - December

Copyright@ Celsius

http://dx.doi.org/10.21614/chirurgia.116.6.700

\title{
Interventional Radiology in Splenic Trauma: If Not Now, Then When?
}

\author{
Dana Paula Venter ${ }^{1}$, Mircea Beuran² ${ }^{*}$, Laurențiu Gulie ${ }^{3}$, Monica Popiel ${ }^{3}$, Mircea Dan Venter ${ }^{4}$, Constantin Oprescu ${ }^{4}$, \\ Costin Minoiu ${ }^{5}$, George Pană ${ }^{3}$, Bogdan Popa ${ }^{5}$, Georgian Tiberiu Tănase ${ }^{4}$
}

\author{
'Division of Pediatric Surgery, $2^{\text {nd }}$ Department of Surgery, Children Emergency Hospital "Grigore Alexandrescu", Bucharest, Romania \\ ${ }^{2}$ Academy of Medical Sciences, full member \\ University of Medicine and Pharmacy "Carol Davila" Bucharest, Department of Surgery, Bucharest, Romania \\ $3^{\text {rd }}$ Department of Surgery, Emergency Hospital Bucharest, Bucharest, Romania \\ ${ }^{3}$ Department of Interventional Radiology, Bucharest Emergency Clinical Hospital, Bucharest, Romania \\ ${ }^{4}$ Department of Surgery, Emergency Clinical Hospital Bucharest, Bucharest, Romania \\ ${ }^{5}$ University of Medicine and Pharmacy "Carol Davila" Bucharest, Department of Interventional Radiology, Bucharest, Romania
}

*Corresponding author:

Mircea Beuran, MD

Professor of Surgery

University of Medicine and

Pharmacy "Carol Davila" Bucharest

E-mail: drmirceabeuran@yahoo.com

\section{Abbreviations:}

AAST OIS: American Association for the Surgery of Trauma - Organ Injury Scale,

AE: angioembolization,

AVF: arterio-venous fistula,

CT: computed tomography,

DA: diagnostic angiography,

DSAE: distal splenic angioembolization,

DSA: diagnostic splenic angiography,

DSR: delayed splenic rupture,

EAST: Eastern Association for the Surgery

of Trauma,

GCS: Glasgow Coma Scale,

ICU: Intensive Care Unit,

IR: interventional radiology,

IVCA: intravenous contrast agent,

PSA: pseudoaneurysm,

PSAE: proximal splenic angioembolization,

SAE: splenic angioembolization,

VR: ventricular rate,

WTA: Western Trauma Association.

\section{Rezumat}

Radiologia intervențională splenică în traumă: dacă nu acum, atunci când?

Introducere: Tratamentul leziunilor contuzive splenice a prezentat schimbări evolutive majore, de la splenectomia de principiu la tratamentul nonoperator si endovascular, "chirurgia cu un cateter". Actual, în Centrele de Traumă, angioembolizarea splenică este considerată intervenția de primă linie în traumă. Acest articol prezintă experiența Spitalului Clinic de Urgență Bucureşti în utilizarea angioembolizării splenice, soluție terapeutică în concordanță cu practica şi literatura contemporană de specialitate.

Metode: Acest studiu retrospectiv cuprinde pacienții cu leziuni splenice prin mecanism contuziv, la care s-a efectuat angiografie diagnostică/terapeutică, internați în Spitalul Cinic de Urgență Bucureşti în perioada ianuarie 2006 - decembrie 2019. Obiectivul principal a fost reprezentat de evaluarea eficacitătii embolizării splenice în controlul hemoragiei posttraumatice şi evaluarea siguranței acesteia în termenii efectelor adverse ale metodei; endpointurile principale ale studiului au fost: mortalitatea posttraumatică, necesitatea unei intervenții chirurgicale (laparoscopice /clasice) pentru rezolvarea sângerării de la nivel splenic, numărul de zile de spitalizare, necesitatea internării mai mult de 1 zi în Clinica de Anestezie şi Terapie Intensivă, ziua în care a început creşterea numărului de trombocite, evoluția para- 
metrilor de laborator (internare, preangiografie, post-angiografie /embolizare, externare). Un endpoint secundar al studiului a fost frecvența complicațiilor care nu au necesitat intervenție chirurgicală.

Rezultate:În perioada menționată la 64 de pacienți tratați non-operator, s-a efectuat angiografia diagnostică (27 de cazuri, grup B) sau terapeutică (37 de cazuri, grup A). 27\% dintre cazuri au avut vârsta $\geq 55$ ani (55-81 ani), predominanța sexului masculin fiind evidentă (63\%). Valoarea medie a scorului de severitate lezională a fost $21,7 \pm 10.4$, iar $71,87 \%$ dintre cazuri au prezentat scorul de severitate lezională $\geq 16$. Gradul lezional splenic (conform American Association for the Surgery of Trauma-Organ Injury Scale) a prezentat valoarea medie 2,95. Gradul lezional splenic a fost semnificativ statistic mai sever la grupul A $(p<0.001)$ iar valorile hemoglobinei preangiografie au fost semnificativ mai scăzute comparativ cu valorile de la internare $(\mathrm{p}<0.001)$ indicând persistența hemoragiei. Eşecurile procedurale s-au produs la 5\% din cazuri, mortalitatea fiind nulă.

Concluzii: Radiologia intervențională splenică este o procedură sigură, eficientă şi rațională. Dezvoltarea protocoalelor terapeutice este necesară pentru a permite utilizarea maximală a acestei proceduri.

Cuvinte cheie: tratament nonoperator, radiologie intervențională, contuzie splenică

\section{Abstract}

Introduction: The treatment of blunt splenic injuries showed major evolutionary changes, from fundamental/ basic splenectomy to nonoperative and endovascular treatment, "catheter surgery". Currently, in Trauma Centers, splenic angioembolization is considered the first-line intervention in trauma. This article presents the Bucharest Emergency Clinical Hospital experience in the use of splenic angioembolization, a therapeutic solution in accordance with contemporary practice and literature.

Methods: This retrospective study includes patients with splenic trauma by blunt mechanism, in which diagnostic / therapeutic angiography was performed, hospitalized in the Clinical Emergency Hospital Bucharest between January 2006 and December 2019. The main endpoints of the study were: post-traumatic mortality, the need for surgery (laparoscopic/classic) to resolve splenic bleeding, the number of days of hospitalization, the need for hospitalization for more than 1 day in the intensive care unit, the day when the platelet count began to increase, the evolution of laboratory parameters (hospitalization, preangiography, postangiography/embolization, discharge). A secondary endpoint of the study was the frequency of complications that did not require surgery.

Results: During the mentioned period in 64 patients treated nonoperatively, diagnostic angiography was performed (27 cases, group B) or therapeutic angiography (37 cases, group A). 27\% of cases were $\geq 55$ years old (55-81 years old), the predominance of males being obvious (63\%). The mean value of the ISS was $21.7 \pm 10.4$, and $71.87 \%$ of cases presented ISS $\geq 16$. The degree of splenic injury (American Association for the Surgery of Trauma-Organ Injury Scale) presented the mean value 2.95 . The degree of splenic lesion was statistically significantly more severe in group A $(\mathrm{p}<0.001)$ and preangiographyhemoglobin values were significantly lower compared to hospitalization values $(\mathrm{p}<0.001)$ indicating the persistence of hemorrhage. Procedural failures occurred in 5\% of cases, with zero mortality.

Conclusions: Splenic interventional radiology is a safe, effective and rational procedure. The development of therapeutic protocols is necessary to allow maximum use of this procedure.

Key words: nonoperative treatment, interventional radiology, blunt splenic injury 


\section{Introduction}

The emergence and development of Regional Trauma Centers, the regionalization of the care of traumatized/polytraumatized patients and the continuous development of diagnostic imaging methods, determined a new thinking and a different approach to the traumatized.

The therapy of traumatic splenic lesions went through several stages - fundamental/ basic splenectomy, conservative splenic surgery (splenorrhaphy, partial splenectomy, subtotal splenectomy, application of local hemostatics), splenectomy followed by intraomental splenic implant, nonoperative treatment, splenic angioembolization (1-8).

Current concept: not all post-traumatic hemoperitoneum should be operated on immediately.

Nonoperative management (NOM) is currently the "gold standard" in splenic trauma.

In hemodynamically stable patients, nonoperative treatment is the optimal strategy and allows the preservation of the organ and its functions, especially the immunological one.

Nonoperative treatment can be used as a single method (in the vast majority of cases) or combined with diagnostic and therapeutic angiography.

\section{Material and Methods}

The study period was January 2006December 2019, and includes patients with tomographically diagnosed splenic lesions in which splenic interventional radiology (angiography, angioembolization) was performed. The study retrospectively analyzes the period 2006-2017 and prospectively the period 2018-2019.

The exclusion criteria were: abdominal/ thoraco-abdominal wounds with splenic involvement, patients who underwent any operative abdominal intervention before angioembolization (AE), patients presented with burns and patients declared dead on arrival or who died within 24 hours after trauma.

All analyzed patients had an initial abdominopelvic CT examination with IVCA (blunt abdominal trauma) or cerebral and thoracoabdomino-pelvic (in case of polytrauma).

All patients who were stable enough underwent a simultaneous dual-phase (arterial and portal phase) CT scan of the thorax, abdomen, and pelvis.

Abdominal CT examination determined:

- splenic lesion grade (AAST OIS 1994 classification-9, completed with the one revised in 2018-10) (Tables 1, 2);

- presence of intrasplenic posttraumatic vascular lesions: active extravasation of

Table 1. AAST splenic injury scale

\begin{tabular}{cll}
\hline Grade* $^{*}$ & Injury type & Description of injury \\
\hline I & Hematoma & Subcapsular $<10 \%$ of surface area \\
\cline { 2 - 3 } & Laceration & Capsular tear $<1 \mathrm{~cm}$ parenchymal depht \\
\hline II & Hematoma & $\begin{array}{l}\text { Subcapsular } 10-50 \% \text { of surface area } \\
\text { Intraparenchymal }<5 \mathrm{~cm} \text { in diameter }\end{array}$ \\
\cline { 2 - 3 } & Laceration & $\begin{array}{l}\text { Capsular tear } 1-3 \mathrm{~cm} \text { parenchymal depht, not involving } \\
\text { trabecular vessels }\end{array}$ \\
\hline III & Hematoma & $\begin{array}{l}\text { Subcapsular }>50 \% \text { of surface area or expanding } \\
\text { Ruptured subcapsular or parenchymal hematoma } \\
\text { Intraparenchymal hematoma } \geq 5 \text { cm or expanding }\end{array}$ \\
\cline { 2 - 3 } & Laceration & $>3$ cm parenchymal depth or involving trabecular vessels \\
\hline IV & Laceration & $\begin{array}{l}\text { Laceration involving segmental or hilar vessels, producing major } \\
\text { devascularization }(>25 \% \text { of spleen) }\end{array}$ \\
\hline V & Laceration & Shattered spleen \\
\cline { 2 - 3 } & Vascular & Hilar vascular injury that devascularizes spleen \\
\hline *Advance one grade for multiple injuries up to grade III &
\end{tabular}


Table 2. Spleen Organ Injury Scale - 2018 Revision

\begin{tabular}{|c|c|c|c|c|}
\hline $\begin{array}{l}\text { AAST } \\
\text { grade }\end{array}$ & $\begin{array}{l}\text { AIS } \\
\text { severity }\end{array}$ & $\begin{array}{l}\text { Imaging criteria } \\
\text { (CT findings) }\end{array}$ & Operative criteria & Pathologic criteria \\
\hline I & 2 & $\begin{array}{l}\text { - Subcapsular hematoma }<10 \% \text { surface area } \\
\text { - Parenchymal laceration }<1 \mathrm{~cm} \text { depth } \\
\text { - Capsular tear }\end{array}$ & $\begin{array}{l}\text { - Subcapsular hematoma }<10 \% \text { surface area } \\
\text { - Parenchymal laceration }<1 \mathrm{~cm} \text { depth } \\
\text { - Capsular tear }\end{array}$ & $\begin{array}{l}\text { - Subcapsular hematoma }<10 \% \text { surface area } \\
\text { - Parenchymal laceration }<1 \mathrm{~cm} \text { depth } \\
\text { - Capsular tear }\end{array}$ \\
\hline II & 2 & $\begin{array}{l}\text { - Subcapsular hematoma } 10-50 \% \text { surface area; } \\
\text { intraparenchymal hematoma }<5 \mathrm{~cm} \\
\text { - Parenchymal laceration } 1-3 \mathrm{~cm}\end{array}$ & $\begin{array}{l}\text { - Subcapsular hematoma } 10-50 \% \text { surface area; } \\
\text { intraparenchymal hematoma }<5 \mathrm{~cm} \\
\text { - Parenchymal laceration } 1-3 \mathrm{~cm}\end{array}$ & $\begin{array}{l}\text { - Subcapsular hematoma } 10-50 \% \text { surface area; } \\
\text { intraparenchymal hematoma }<5 \mathrm{~cm} \\
\text { - Parenchymal laceration } 1-3 \mathrm{~cm}\end{array}$ \\
\hline III & 3 & $\begin{array}{l}\text { - Subcapsular hematoma }>50 \% \text { surface area; } \\
\text { ruptured subcapsular or intraparenchymal } \\
\text { hematoma } \geq 5 \mathrm{~cm} \\
\text { - Parenchymal laceration }>3 \mathrm{~cm} \text { depth }\end{array}$ & $\begin{array}{l}\text { - Subcapsular hematoma }>50 \% \text { surface area or } \\
\text { expanding; ruptured subcapsular or } \\
\text { intraparenchymal hematoma } \geq 5 \mathrm{~cm} \\
\text { - Parenchymal laceration }>3 \mathrm{~cm} \text { depth }\end{array}$ & $\begin{array}{l}\text { - Subcapsular hematoma }>50 \% \text { surface area; } \\
\text { ruptured subcapsular or intraparenchymal } \\
\text { hematoma } \geq 5 \mathrm{~cm} \\
\text { - Parenchymal laceration }>3 \mathrm{~cm} \text { depth }\end{array}$ \\
\hline IV & 4 & $\begin{array}{l}\text { - Any injury in the presence of a splenic } \\
\text { vascular injury or active bleeding confined } \\
\text { within splenic capsule } \\
\text { - Parenchymal laceration involving segmental or } \\
\text { hilar vessels producing }>25 \% \text { devascularization }\end{array}$ & $\begin{array}{l}\text { - Parenchymal laceration involving segmental or } \\
\text { hilar vessels producing }>25 \% \text { devascularization }\end{array}$ & $\begin{array}{l}\text { - Parenchymal laceration involving segmental or } \\
\text { hilar vessels producing }>25 \% \text { devascularization }\end{array}$ \\
\hline V & 5 & $\begin{array}{l}\text { - Any injury in the presence of splenic vascular } \\
\text { injury with active bleeding extending beyond } \\
\text { the spleen into the peritoneum } \\
\text { - Shattered spleen }\end{array}$ & $\begin{array}{l}\text { - Hilar vascular injury which devascularizes } \\
\text { the spleen } \\
\text { - Shattered spleen }\end{array}$ & $\begin{array}{l}\text { - Hilar vascular injury which devascularizes } \\
\text { the spleen } \\
\text { - Shattered spleen }\end{array}$ \\
\hline
\end{tabular}

Vascular injury is defined as a pseudoaneurysm or arteriovenous fistula and appears as a focal collection of vascular contrast that decreases in attenuation with delayed imaging. Active bleeding from a vascular injury presents as vascular contrast, focal or diffuse, that increases in size or attenuation in delayed phase. Vascular thrombosis can lead to organ infarction.

Grade based on highest grade assessment made on imaging, at operation or on pathologic specimen.

More than one grade of splenic injury may be present and should be classified by the higher grade of injury.

Advance one grade for multiple injuries up to a grade III.

IVCA, PSA, AVF, vessel truncation;

- associated visceral lesions;

- estimation of hemoperitoneum volume.

Minimal hemoperitoneum was defined as intra-abdominal blood located only in the perisplenic area, while a significant hemoperitoneum is exceeding the perisplenic area. We used two methods for the appraisement of hemoperitoneum::

- Classification of hemoperitoneum, taking into account 7 intraperitoneal spaces: right subphrenic, left subphrenic, subhepatic, right paracolic, left paracolic, pelvis, intramesenteric $(11,12)$.

- 1-2 intraperitoneal spaces $=$ small $(250$ $\mathrm{ml})$;

- 2-4 intraperitoneal spaces $=$ moderate (250-500 ml);

- $>4$ intraperitoneal spaces $=$ large (> $500 \mathrm{ml}$ ).

- CT classification of hemoperitoneum by Hagiwara (13):

- 0 - absent hemoperitoneum;

- 1+, present in a single anatomical area (hepatorenal, perihepatic, perisplenic);

- $2+, \geq 2$ areas (parieto-colic gutters, lateral paravesical);
- $3+$, the entire pelvis;

- presence of associated intra-abdominal lesions.

In general, patients haemodynamically stable enough to come to the interventional suite and without another indication for laparotomy, with contrast extravasation or pseudoaneurysm on CT scan, are considered for $\mathrm{AE}$ in our unit; patients with grade IV or $\mathrm{V}$ injuries without contrast extravasation or pseudoaneurysm, patients with ongoing transfusion requirements, and transient responders to fluid resuscitation are also considered for AE. Management decisions are made on a case-by-case scenario. $\mathrm{AE}$ is performed in the interventional radiology theatre under local or general anesthesia.

\section{Angiographic Procedures Were Classified Into:}

- diagnosis (DA diagnostic angiography) and

- therapeutic (SAE splenic angioembolization),

aiming the

- indication of embolization; 
- SAE technique: proximal (PSAE), distal (DSAE), combined, repeated;

- the material used for AE.

The SAE indication was established by the interventional radiologist together with the chief surgeon of the trauma team and the choice of the modality and the material used for the procedure belonged to the interventional radiologist.

Patients undergoing NOM were monitored with observations performed hourly initially. Serial abdominal examinations were conducted at least twice a day. Failure of NOM was considered as new haemodynamic instability resulting from further splenic bleeding; these patients would undergo an intervention, either $\mathrm{AE}$ or splenectomy. Failure of $\mathrm{AE}$ was considered as a new haemodynamic instability resulting from further splenic bleeding and necessitating either further attempted $\mathrm{AE}$ or splenectomy.

In the cases in which the post-procedural CT examination was repeated, the following were followed:

- diagnosis of a complication (infarction/ splenic abscess, pleural effusion);

- persistence of the initial vascular lesion or the appearance of a new lesion(s).

Follow-up imaging was only performed if clinically indicated; the clinical deterioration required the repetition of the $\mathrm{CT}$ examination (post-procedural complication, continuation of bleeding).

The following definitions are used to clarify the terminology used:

- isolated splenic injury $=$ single abdominal lesion/in the absence of plurisystemic lesions that influence the prognosis.

- low splenic lesion grade = grade 1,2;

- severe splenic lesion grade = grade $3,4,5$;

- immediate laparotomy = performed in the first 24 hours after trauma;

- delayed laparotomy $=$ performed more than 24 hours after admission;

- $\mathrm{NOM}=$ intentional observation of a demonstrated post-traumatic splenic injury;

- NOM failure = patient with delayed laparotomy performed after 3 stable hematocrit determinations/24 hours; the need for surgery in a patient treated nonoperatively with / without SAE;

- clinical/paraclinical evidence of persistent hemorrhage requiring laparotomy for hemostasis or delayed diagnosis of a major intra-abdominal lesion;

- stable hematocrit = initial and tertiary measurement without differences greater than / equal to $3 \%$;

- polytrauma / severe trauma $=$ ISS $>17$

- successful NOM = patient discharged with the spleen "in situ" and without the indication of a splenic surgery at the most recent clinical control;

- initial SAE = angioembolization performed in the first 12 hours after hospitalization;

- technical failure of angioembolization $=$ impossibility of cannulation and embolization of the splenic artery; the experience of the interventional radiologist decreases this risk.

Radiological "hard signs" are defined as the presence of contrast extravasation or pseudoaneurysm on the initial CT scan. Haemodynamic instability on admission was defined as pulse rate of 120 beats per minute or more or systolic blood pressure less than $90 \mathrm{mmHg}$ with the presence of skin vessels vasoconstriction (cold, sweaty extremities, decreased capillary refilling), altered consciousness and possible tachypnea; patients with transient haemodynamic stability should be considered haemodynamically unstable.

\section{Study Endpoints}

The main objective was to evaluate the effectiveness of splenic embolization in the control of post-traumatic bleeding and to evaluate its safety in terms of the adverse effects of the method. The main endpoints of the study were: post-traumatic mortality, the need for surgery (laparoscopic/classic) to resolve splenic bleeding, the number of days of hospitalization, the need for hospitalization for more than 1 day in the ICU, the day when the platelet count began to increase, the 
evolution of laboratory parameters (hospitalization, preangiography, postangiography / embolization, discharge). A secondary endpoint of the study was the frequency of complications that did not require surgery.

The purpose of the analysis was the splenic rescue, being studied the degree of lesion, the volume of hemoperitoneum and the presence of intrasplenic vascular lesions.

The variables monitored and analyzed were: age, sex, etiology of trauma, injury mechanism, presence / absence of shock, shock index value, GCS, degree of splenic injury/hemoperitoneum, applied treatment, associated lesions, morbidity, mortality, length of hospital stay.

International trauma guidelines (EAST, WTA) and clinical judgment / assessment have been the basis for therapeutic decisions.

Splenic salvage was considered as patient discharge with the spleen in situ.

\section{Statistical Analysis}

We used software R, version 4.0.2 Copyright (C) 2020 The $R$ Foundation for Statistical Computing, R Core Team (2020). R: A language and environment for statistical computing. $\mathrm{R}$ Foundation for Statistical Computing, Vienna, Austria. URL https://www.R-project.org.

Data are reported as means (standard deviations), medians (interquartile range), or percentages.

Categorical data were analysed with Chisquare tests and Fisher's exact test when expected frequencies in contingency tables were below five. Differencies in demographic and clinical characteristics between patients with or without SAE or DA were determined by $\chi^{2}$ tests for categorical variables and either $t$ tests for continuous variables. The SmirnovKolmogorov test was performed in order to verify if the variables fit the same distribution. The significance level considered was $95 \%$ ( $p$-value less than 0.05).

\section{Results}

In the Department of Surgery of the Bucharest Emergency Clinical Hospital, in the period
2006-2019, diagnostic splenic angiography (DSA) and SAE were performed in 64 patients.

During the mentioned period in 64 patients treated nonoperatively, diagnostic angiography was performed (27 cases, group B) or therapeutic angiography (37 cases, group A).

During the mentioned period we observed the following tendencies: the constant increase of the proportion of patients treated nonoperatively, an initial increase of the cases in which the splenic interventional angiography was performed and the decrease of the cases in which the emergency splenectomy was performed.

The decrease in cases in which splenic interventional angiography was performed is explained by the lack of an internal therapeutic protocol, the decision of trauma surgeons and technical problems at the Interventional Radiology Laboratory (deficiencies in the existence of necessary catheters /microcatheters and embolization materials).

The demographic and clinical characteristics of the patients are presented in Table 3.

It is observed that there were patients from all age categories, the averages in the two groups revealing that the typical patient is a young-middle-aged adult.

$27 \%$ of cases were $\geq 55$ years old $(55-81$ years old), the predominance of males being obvious $(63 \%)$. The result supports the findings of other studies that highlight the increase in the number of traumatized patients in old age.

There is a similarity of the distribution by sex between the two groups, with the predominance of males, a characteristic of traumatic pathologies (62\% males in group $\mathrm{A}$, $63 \%$ in group B).

From the point of view of the injury mechanism, we analyzed whether it was a road accident or other causes; in patients in group A, the etiology of the road accident was twice as common.

The median of the ISS was 19.0 [4.00, 50.0], which highlights the severity of the cases $72 \%$ of cases with an ISS $\geq 16$. The median value of the shock index $(0.800[0.500,1.80])$ places these cases in the second class, average shock. 
Table 3. Demographics (A) and Clinical Characteristics (B) of all patients

\begin{tabular}{|c|c|c|c|c|}
\hline A. Demographics & Group $A(n=37)$ & Group $B(n=27)$ & Global $(n=64)$ & $\mathbf{p}$ \\
\hline Age, median, (IQR), y & $37.0[12.0,78.0]$ & $42.0[13.0,81.0]$ & $38.0[12.0,81.0]$ & NS \\
\hline mean $\pm S D, y$ & $39.9( \pm 18.9)$ & $43.6( \pm 17.1)$ & $41.5( \pm 18.1)$ & \\
\hline Male, n (\%) & $23(62.2 \%)$ & $17(63.0 \%)$ & $40(62.5 \%)$ & NS \\
\hline \multicolumn{5}{|l|}{ Injury mechanism, n (\%) } \\
\hline MVC, pedestrian struck & $5(13.5 \%)$ & $2(7.4 \%)$ & $7(10.9 \%)$ & NS \\
\hline Other & $32(86.5 \%)$ & $25(92.6 \%)$ & $57(89,1 \%)$ & NS \\
\hline \multicolumn{5}{|l|}{ Injury characteristics, } \\
\hline mean $\pm S D$ & $20.8( \pm 10.8)$ & $23.0( \pm 9.92)$ & $21.7( \pm 10.4)$ & NS \\
\hline \multicolumn{5}{|l|}{ B.Clinical Characteristics } \\
\hline Vital signs & $116[55.0,160]$ & $110[80.0,165]$ & $112[55.0,165]$ & NS \\
\hline ED SBP, median (IQR) & $115( \pm 19.7)$ & $115( \pm 24.5)$ & $115( \pm 21.7)$ & NS \\
\hline mean $\pm S D$ & $95.0[65.0,110]$ & $98.0[78.0,160]$ & $96.0[65.0,160]$ & NS \\
\hline \multicolumn{5}{|l|}{ ED HR, } \\
\hline median (IQR) & $0.800[0.500,1.80]$ & $0.900[0.500,1.50]$ & $0.800[0.500,1.80]$ & NS \\
\hline mean $\pm S D$ & $0.839( \pm 0.226)$ & $0.915( \pm 0.246)$ & $0.871( \pm 0.236)$ & NS \\
\hline \multicolumn{5}{|l|}{ ED shock index, } \\
\hline median (IQR) & $15.0[3.00,15.0]$ & $15.0[6.00,15.0]$ & $15.0[3.00,15.0]$ & NS \\
\hline mean $\pm S D$ & $14.0( \pm 2.75)$ & $14.0( \pm 2.30)$ & $14.0( \pm 2.55)$ & NS \\
\hline \multicolumn{5}{|l|}{ ED GCS median (IQR) } \\
\hline AAST injury grade, $n$ (\%) & & & & $p=0.0008$ \\
\hline 1 & $0(0 \%)$ & $4(14,8 \%)$ & $4(6.3 \%)$ & \\
\hline 2 & $4(10.8 \%)$ & $6(22.2 \%)$ & $10(15.6 \%)$ & \\
\hline 3 & $24(64.9 \%)$ & $12(44.4 \%)$ & $36(56.3 \%)$ & \\
\hline 4 & $8(21.6 \%)$ & $5(18.5 \%)$ & $13(20.3 \%)$ & \\
\hline 5 & $1(2.7 \%)$ & $0(0 \%)$ & $1(1.6 \%)$ & \\
\hline \multicolumn{5}{|c|}{ Degree of hemoperitoneum $\mathrm{n}(\%)$} \\
\hline small & $13(35.1 \%)$ & $9(33.3 \%)$ & $22(34.4 \%)$ & \\
\hline moderate & $15(40.5 \%)$ & $13(48.1 \%)$ & $28(43.8 \%)$ & \\
\hline large & $9(24.3 \%)$ & $5(18.5 \%)$ & $14(21.9 \%)$ & \\
\hline \multicolumn{5}{|l|}{ Hagiwara } \\
\hline 0 & $5(13.5 \%)$ & $2(7.4 \%)$ & $7(10.9 \%)$ & \\
\hline $1+$ & $8(21.6 \%)$ & 7 (25.9\%) & $15(23.4 \%)$ & \\
\hline $2+$ & $10(27.0 \%)$ & $11(40.7 \%)$ & $21(32.8 \%)$ & \\
\hline $3+$ & $14(37.8 \%)$ & $7(25.9 \%)$ & $21(32.8 \%)$ & \\
\hline \multicolumn{5}{|l|}{ Blood transfusion, n (\%) } \\
\hline yes & $19(51.4 \%)$ & $14(51.9 \%)$ & $33(51.6 \%)$ & \\
\hline no & $18(48.6 \%)$ & $13(48.1 \%)$ & $31(48.4 \%)$ & \\
\hline \multicolumn{5}{|l|}{ Complications, $\mathrm{n}(\%)$} \\
\hline yes & $20(54.1 \%)$ & $11(40.7 \%)$ & $31(48.4 \%)$ & NS \\
\hline no & $17(45.9 \%)$ & $16(59.3 \%)$ & $33(51.6 \%)$ & NS \\
\hline \multicolumn{5}{|l|}{ Treatment failure, $\mathrm{n}(\%)$} \\
\hline yes & $1(2.7 \%)$ & $2(7.4 \%)$ & $3(4.7 \%)$ & NS \\
\hline no & $36(97.3 \%)$ & $25(92.6 \%)$ & $61(95.3 \%)$ & NS \\
\hline \multicolumn{5}{|c|}{ Non-abdominal surgery, $\mathrm{n}(\%)$} \\
\hline yes & $9(24.3 \%)$ & $11(40.7 \%)$ & $20(31.3 \%)$ & 0.1617 \\
\hline no & $28(75.7 \%)$ & $16(59.3 \%)$ & $44(68.8 \%)$ & \\
\hline \multicolumn{5}{|l|}{ Hemodynamic shock, n (\%) } \\
\hline yes & $2(5.4 \%)$ & $6(22.2 \%)$ & $8(12.5 \%)$ & 0.0611 \\
\hline no & $35(94.6 \%)$ & $21(77.8 \%)$ & $56(87.5 \%)$ & \\
\hline \multicolumn{5}{|l|}{ ICU days } \\
\hline median (IQR) & $0[0,18.0]$ & $0[0,18.0]$ & $0[0,18.0]$ & \\
\hline mean $\pm S D$ & $2.22 \pm 4.24$ & $3.81 \pm 5.26$ & $2.89 \pm 4.72$ & \\
\hline \multicolumn{5}{|l|}{ Department' Surgery days } \\
\hline median $(\mathrm{IQR})$ & $9.00[1.00,37.0]$ & $9.00[2.00,30.00]$ & $9.00[1.00,37.0]$ & \\
\hline mean $\pm S D$ & $10.2 \pm 6.33$ & $10.4 \pm 6.25$ & $10.3 \pm 6.25$ & \\
\hline \multicolumn{5}{|l|}{ AAST OIS 2018} \\
\hline median $[\mathrm{IQR}]$ & $4.00[2.00,5.00]$ & $3.00[1.00,5.00]$ & $3.00[1.00,5.00]$ & \\
\hline mean $\pm S D$ & $3.73 \pm 0.838$ & $2.89 \pm 1.15$ & $3.38 \pm 1.06$ & \\
\hline
\end{tabular}


Table 4. Changes of the splenic grade after implementation of AAST-OIS 2018 revision

\begin{tabular}{lcc}
\hline Grade & AAST $\mathbf{1 9 9 4}(\mathbf{N})^{*}$ & AAST 2018 (N) ${ }^{*}$ \\
\hline 1 & 4 & 4 \\
\hline 2 & 10 & 7 \\
\hline 3 & 36 & 23 \\
\hline 4 & 13 & 21 \\
\hline 5 & 1 & 9 \\
\hline${ }^{*}(\mathrm{~N})-$ number of cases & &
\end{tabular}

The splenic lesion grade AAST-OIS showed an average value of 2.95 . There were 14 cases of minor injuries (grade I- 4 cases, grade II-10 cases) and 50 cases of severe injuries (grade III-36 cases; grade IV-13 cases; grade $\mathrm{V}-1$ case).

The predominance of grades $3(56 \%)$ and 4 $(20 \%)$ is observed, SAE being performed in 32 cases $(50 \%)$. From the table it is observed that the low degrees of rupture were characteristic of group B, while the high degrees of rupture were characteristic of group A.

Applying the revised AAST-OIS classification (2018), the lesion grade increased, the number of cases for each grade being (Table 4):

In general, the degree of splenic lesion advanced by 1 unit: grade $3 \rightarrow 4: 10$ cases; grade $4 \rightarrow 5: 3$ cases; grade $2 \rightarrow 3: 1$ case or with 2-3 units: grade $3 \rightarrow 5: 4$ cases; grade $2 \rightarrow$ 4: 1 case; grade $2 \rightarrow 5: 1$ case. Globally, retroactively applying the new AAST-OIS classification, 20 cases have progressed lesion emphasizing the importance of the presence of active bleeding and intrasplenic vascular lesions.

The evaluation of the degree of hemoperitoneum was performed by the classical method $(11,12)$ and by the one described by Hagiwara $(13,14)$ in order to be able to appreciate its value as accurately as possible).

In group A (angioembolization) there was a higher frequency of significant intraperitoneal hemorrhages, while the mean intraperitoneal hemorrhages predominated in group B (diagnostic angiography), a fact confirmed in both classifications used.

Given the characteristics of the two groups, for the comparison of the severity of splenic traumas (AAST-OIS) a replacement sampling procedure (bootstrap) was used for the difference of the two averages of the distributions (SE is the average error, IC95\% was calculated as the difference between the $97.5 \%$ and $2.5 \%$ quantiles of the bootstrap distribution). The differences were statistically significant $(p<$ 0.001 ), in patients in group A the trauma was more severe.

The analysis of hemodynamic parameters at hospitalization (SBP - systolic blood pressure and ventricular rate - VR) revealed normal values, a finding that emphasizes a correct indication of the procedures (hemodynamically stable patients at the time of indication/performing the interventional radiological procedure).

Laboratory examinations (Table 5) were studied in 4 moments: at admission, before the radiological procedure, post-procedural and discharge; practically the average values of these parameters (hemoglobin) decreased from the average value of $11.4 \mathrm{~g} / \mathrm{dl}( \pm 2.28)$ at admission to $9.98 \mathrm{~g} / \mathrm{dl}( \pm 1.78)$ postprocedural reduction also found in the values of hematocrit and platelets with a stabilization of them at discharge.

A first analysis investigated the clinicalhemodynamic evolution of patients with splenic trauma, separately on each batch, using a comparison between in-patient $\mathrm{Hb}$ values and $\mathrm{Hb}$ values before performing angiography. As measurements were performed in the same patient at different times, the test used was Paired $\mathrm{T}$ ( $\mathrm{T}$ test for correlated samples), which revealed that $\mathrm{Hb}$ values before angiography were statistically significantly lower compared to the time of hospitalization, indicating a evolution of bleeding in these patients $(p<0.001)$. The comparison between the pre-angiography $\mathrm{Hb}$ values and the post-angiography $\mathrm{Hb}$ values for each group (the inferential test was Paired T) showed that there were no differences with statistical significance, the evolution of bleeding seemed to be stopped ( $p=0.290$ for group $\mathrm{A}$, $\mathrm{p}=0.181$ for group B).

The comparison between the $\mathrm{Hb}$ values Post-Angiography with the $\mathrm{Hb}$ values at discharge, for each group (inferential test Paired T) revealed that there were no 
Table 5. Levels of laboratory examinations

\begin{tabular}{|c|c|c|c|}
\hline & Group A & Group B & Total \\
\hline \multicolumn{4}{|l|}{ A.ED } \\
\hline \multicolumn{4}{|l|}{ hemoglobin } \\
\hline mean $\pm \mathrm{SD}, \mathrm{g} / \mathrm{dl}$ & $11.8 \pm 2.18$ & $11.0 \pm 2.40$ & $11.4 \pm 2.28$ \\
\hline median, [IQR], g/dl & $11.9[6.30,15.7]$ & $11.3[4.50,14.3]$ & $11.8[4.50,15.7]$ \\
\hline \multicolumn{4}{|l|}{ hematocrit } \\
\hline mean $\pm S D, \%$ & $35.6 \pm 7.55$ & $33.6 \pm 6.85$ & $34.7 \pm 7.28$ \\
\hline median, [IQR], \% & $36.7[14.9,54.0]$ & $34.9[14.7,42.7]$ & $36.1[14.7,54.0]$ \\
\hline \multicolumn{4}{|l|}{ leucocytes } \\
\hline mean $\pm \mathrm{SD}, / \mathrm{mm}^{3}$ & $12.8 \pm 5.05$ & $14.9 \pm 6.07$ & $13.7 \pm 5.55$ \\
\hline median, [IQR], $/ \mathrm{mm}^{3}$ & $12.5[4.20,29.9]$ & $14.5[4.80,28.4]$ & $13.1[4.20,29.9]$ \\
\hline \multicolumn{4}{|l|}{ platelets } \\
\hline mean $\pm \mathrm{SD}, / \mathrm{mm}^{3}$ & $219 \pm 66.3$ & $262 \pm 112$ & $236 \pm 89.8$ \\
\hline median, [IQR], /mm³ & $211[74.0,372]$ & $229[41.0,543]$ & $222[41.0,543]$ \\
\hline \multicolumn{4}{|l|}{ B. Before Angio } \\
\hline \multicolumn{4}{|l|}{ hemoglobin } \\
\hline mean $\pm S D, g / d l$ & $10.5 \pm 2.23$ & $9.79 \pm 2.38$ & $10.2 \pm 2.30$ \\
\hline median, [IQR], g/dl & $10.7[6.10,14.0]$ & $9.50[4.60,13.7]$ & $10.3[4.60,14.0]$ \\
\hline \multicolumn{4}{|l|}{ hematocrit } \\
\hline mean $\pm \mathrm{SD}, \%$ & $31.9 \pm 6.56$ & $29.4 \pm 6.62$ & $30.9 \pm 6.65$ \\
\hline median, [IQR], \% & $32.7[19.3,41.9]$ & $29.0[15.3,41.2]$ & $31.4[15.3,41.9]$ \\
\hline \multicolumn{4}{|l|}{ leucocytes } \\
\hline mean $\pm \mathrm{SD}, / \mathrm{mm}^{3}$ & $10.8 \pm 4.17$ & $12.1 \pm 6.36$ & $11.3 \pm 5.16$ \\
\hline median, [IQR], $/ \mathrm{mm}^{3}$ & $10.5[4.20,20.2]$ & $9.50[6.30,28.4]$ & $10.2[4.20,28.4]$ \\
\hline \multicolumn{4}{|l|}{ platelets } \\
\hline mean $\pm \mathrm{SD}, / \mathrm{mm}^{3}$ & $200 \pm 70.1$ & $222 \pm 118$ & $209 \pm 92.1$ \\
\hline median, [IQR], $/ \mathrm{mm}^{3}$ & $186[78.0,363]$ & $196[32.0,568]$ & $188[32.0,568]$ \\
\hline \multicolumn{4}{|l|}{ C. After Angio } \\
\hline \multicolumn{4}{|l|}{ hemoglobin } \\
\hline mean $\pm S D, g / d l$ & $10.2 \pm 1.87$ & $9.52 \pm 1.53$ & $9.98 \pm 1.78$ \\
\hline median, [IQR], g/dl & $10.4[6.00,14.7]$ & $9.20[7.80,12.9]$ & $9.70[6.00,14.7]$ \\
\hline \multicolumn{4}{|l|}{ hematocrit } \\
\hline mean $\pm S D, \%$ & $31.0 \pm 5.35$ & $29.2 \pm 4.51$ & $30.4 \pm 5.13$ \\
\hline median [IQR], \% & $32.3[17.8,42.7]$ & $28.4[23.5,39.7]$ & $29.6[17.8,42.7]$ \\
\hline \multicolumn{4}{|l|}{ leucocytes } \\
\hline \multicolumn{4}{|l|}{$\begin{array}{l}\text { mean } \pm \mathrm{SD}, / \mathrm{mm}^{3} \\
\text { median, }[\mathrm{IQR}], / \mathrm{mm}^{3}\end{array}$} \\
\hline \multicolumn{4}{|l|}{ platelets } \\
\hline mean $\pm \mathrm{SD}, / \mathrm{mm}^{3}$ & $196 \pm 63.4$ & $197 \pm 110$ & $196 \pm 80.3$ \\
\hline median, [IQR], $/ \mathrm{mm}^{3}$ & $186[86.0,356]$ & $177[58.0,416]$ & $185[58.0,416]$ \\
\hline \multicolumn{4}{|l|}{ D. Increased platelets } \\
\hline mean $\pm S D$, day & $2.26 \pm 1.24$ & $3.10 \pm 0.968$ & $2.56 \pm 1.21$ \\
\hline median, [IQR], day & $2.00[1.00,6.00]$ & $3.00[2.00,5.00]$ & $2.00[1.00,6.00]$ \\
\hline \multicolumn{4}{|l|}{ E. Discharge } \\
\hline \multicolumn{4}{|l|}{ hemoglobin } \\
\hline mean $\pm \mathrm{SD}, \mathrm{g} / \mathrm{dl}$ & $10.5 \pm 1.49$ & $10.1 \pm 1.46$ & $10.3 \pm 1.48$ \\
\hline median, [IQR], g/dl & $10.6[8.00,14.7]$ & $10.1[8.00,13.0]$ & $10.5[8.00,14.7]$ \\
\hline \multicolumn{4}{|l|}{ hematocrit } \\
\hline mean $\pm S D, \%$ & $32.0 \pm 4.24$ & $30.7 \pm 4.08$ & $31.5 \pm 4.20$ \\
\hline median [IQR], \% & $32.4[24.2,42.7]$ & $30.6[24.3,39.0]$ & $31.2[24.2,42.7]$ \\
\hline leucocytes & & & \\
\hline mean $\pm \mathrm{SD}, / \mathrm{mm}^{3}$ & $11.5 \pm 4.13$ & $8.74 \pm 2.21$ & $10.4 \pm 3.75$ \\
\hline median, [IQR], $/ \mathrm{mm}^{3}$ & $11.1[4.70,18.1]$ & $9.50[4.80,12.3]$ & $10.0[4.70,18.1]$ \\
\hline platelets & & & \\
\hline mean $\pm \mathrm{SD}, / \mathrm{mm}^{3}$ & $427 \pm 220$ & $318 \pm 127$ & $386 \pm 196$ \\
\hline median, [IQR], $/ \mathrm{mm}^{3}$ & $346[106,894]$ & $300[114,572]$ & $332[106,894]$ \\
\hline
\end{tabular}


differences with statistical significance, in patients there were no hemorrhagic complications during hospitalization $(\mathrm{p}=0.309$ for group $\mathrm{A}, \mathrm{p}=0.268$ for group $\mathrm{B}$ ). The analysis showed that, for both methods of therapy, active bleeding was stopped, so the methods were effective for splenic trauma.

Finally, the days of hospitalization were analyzed according to the period of hospitalization in the Department of Surgery, Intensive Care Unit to which was added the total period of hospitalization.

The median duration of hospitalization was 11.0 [4.00. 63.0] days.

Angiographic findings showed:

- active bleeding: 10 cases;

- active bleeding + splenic inhomogeneity: 9 cases;

- active bleeding + splenic inhomogeneity + AVF: 1 case;

- splenic inhomogeneity: 32 cases;

- normal splenic appearance: 12 cases.

The indications for diagnostic angiography were represented by:

- extravasation of the extra- or intrasplenic contrast agent in the hemodynamically stable patient;

- intrasplenic vascular lesions: PSA and AVF;

- splenic injuries grade 3, 4, 5;

- unexplained decrease in hematocrit in the absence of other lesions;

- large hemoperitoneum;

- aggravation of the CT initial image.

SAE was performed in 37 cases (group A) and diagnostic splenic angiography in 27 cases (group B). The decision to perform the SAE belonged exclusively to the interventional radiologist.

In patients in group A, PSAE was performed in 19 cases and DSAE in 18 cases using:

- temporary embolic materials: Gelfoam ${ }^{\circledR}$ (Gelfoam, Pfizer, New York, NY) in 25 cases or TachoSil ${ }^{\circledR}$ in 11 cases;

- definitive embolic materials: metallic coils in 1 case (Figs. 1, 2).

In 17 cases, multiple angiography was performed (in the same session) (Table 6).

Repetition of splenic angiography was

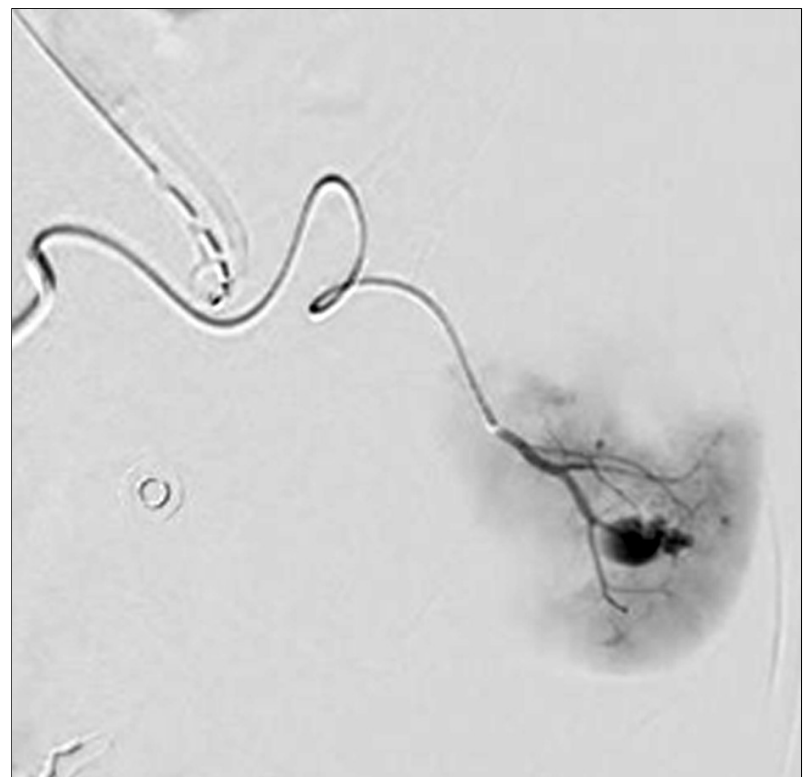

Figure 1. Bilobated pseudoaneurysm, $8 \mathrm{~mm} / 5 \mathrm{~mm}$ dimensions, in the lower splenic pole

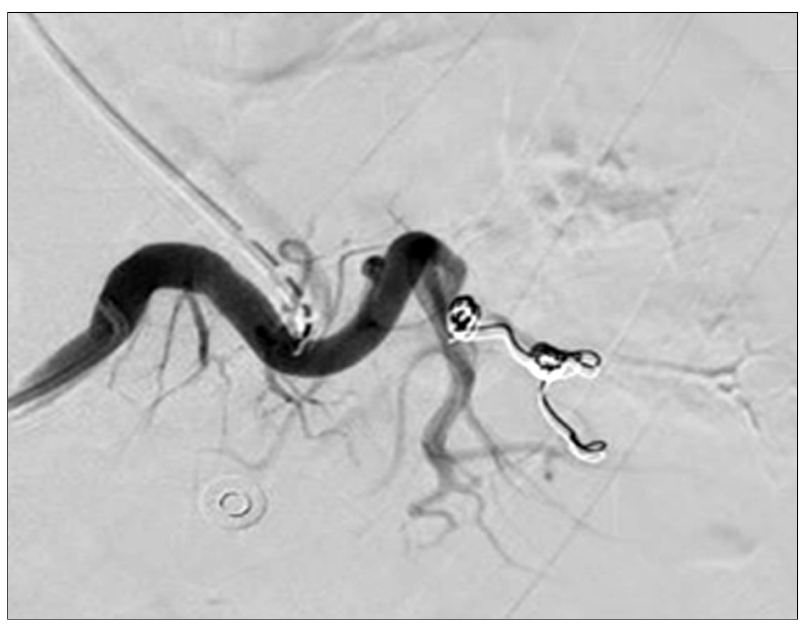

Figure 2. Postprocedural appearance

(supraselective microcoils embolization)

Table 6. Cases with multiple angiography (in the same session with splenic angiography)

\begin{tabular}{lll}
\hline Number & Organ/Zone & Procedure \\
\hline 3 & Pelvis & $\begin{array}{l}\text { 2 embolizations } \\
\text { 1 diagnostic }\end{array}$ \\
\hline 6 & Liver & 6 embolizations \\
\hline 2 & Liver+kidney & 2 liver embolizations \\
\hline 2 & Kydney & $\begin{array}{l}\text { 1 left renal artery angiography } \\
\text { 1 bilateral renal arteries angiography }\end{array}$ \\
\hline 1 & Neck & 1 left internal carotid artery angiography \\
\hline 1 & Axilla & 1 left axillary artery angiography \\
\hline 1 & Pelvis & 1 right common iliac artery angiography \\
\hline 1 & Abdomen & 1 aortography \\
\hline Total & & 10 embolizations \\
& & 7 angiographies \\
\hline
\end{tabular}


performed in 3 cases in which MRI examination revealed the appearance of postprocedural PSA.

There were 13 minor complications (fever, low-grade fever) in the post-embolization syndrome and 18 major complications (9 pleurisy, 6 respiratory infections, 1 urinary tract infection, 1 postprocedural splenic pseudocyst and 1 case of sepsis with positive blood cultures), in total $48 \%$ complications ( $54 \%$ of these belonged to group A). Although the percentage of complications was higher in group A of patients, the bidirectional $\chi^{2}$ (chisquare) test for two independent proportions showed that the difference is without statistical significance $\left(\chi^{2}=1.10\right.$, degrees of freedom $=1$, $\mathrm{p}=0.292)$.

Procedural failures accounted for $5 \%$ (3 cases): continued bleeding (1 case) which required exploratory laparotomy, splenectomy and pancreatography; lack of angiographic evidence of splenic hemorrhage (1 case) solved by exploratory laparoscopy and application of a local hemostatic and a technical failure (impossibility of splenic artery catheterization) solved by splenectomy.

Fisher's exact bidirectional test for two independent proportions showed that the difference is of no statistical significance $(p=0.568)$.

Finally, we performed a comparison between the performance of different diagnostic methods for post-traumatic bleeding in the splenic level. Angiography (considered a gold standard) and CT examination were compared. We considered that the performance of the angiography is $100 \%$ (with no false positive or false negative cases) and we have compared with it the CT performance (see Table $)$ The comparison was made using the Cohen Kappa coefficient, and showed the superiority of

Table 7. Comparison of the active bleeding (Angiography versus CT)

\begin{tabular}{lccc}
\hline & & \multicolumn{2}{c}{$\begin{array}{c}\text { Active bleeding } \\
\text { (Angiography) }\end{array}$} \\
\cline { 2 - 4 } & & Yes & No \\
\hline Active bleeding (CT) & Yes & 14 & 9 \\
\hline & No & 9 & 35 \\
\hline
\end{tabular}

angiography in diagnosing active splenic hemorrhage (Kappa coefficient value 0.48, IC $95 \%=[0.25,0.70])$.

\section{Discussion}

Undiagnosed / late diagnosed posttraumatic abdominal arterial hemorrhage is the main cause of the unfavorable evolution of patients. The leading cause of death in traumatized patients within the first 24 hours of admission (15) remains the continous / persistent bleeding. The solution is represented by early diagnosis and therapy by endovascular techniques, laparotomy or a combination of these (16). The decision must be made quickly and is based on clinical experience / insight and recognition of the lesion pattern.

According to the same author (16) there are important trauma centers that consider arterial embolization a component of primary resuscitation, interventional radiology requiring a multidisciplinary approach in which the trauma surgeon and radiologist must understand the indications and limitations of the procedure. By embolization, an intentional and controlled vascular obliteration is performed in order to stop an arterial hemorrhage (17).

The concept of "splenic angiographic hemostasis" was first introduced by Sclafani (18) in 1981.

Currently, it is considered that angiography (diagnostic and therapeutic) is part of the NOM of splenic trauma (19-23).

Angiographic procedures are diagnostic and therapeutic, the latter being performed with the intention of vascular embolization and stopping hemorrhage. Digital subtraction angiography allows a quick and accurate diagnosis, representing the trauma standard (24), the method reducing the time required for examination, decreasing the amount of IVCA used and the irradiation dose.

SAE increased NOM success by stopping splenic hemorrhage and preventing DSR $(25,26)$ and reduced the risk of splenectomy by more than $18 \%(27,28)$, a fact recently confirmed by Frandon (29). 
The procedure is used in hemodynamically stable / easily stabilizable patients under close surgical supervision and with the possibility of surgery at any time. A particular advantage of angiography is the possibility of treating other concomitant vascular lesions (including stent implants). It should be understood from the outset that $\mathrm{AE}$ is a procedure that requires time and an increased volume of IVCA.

The selective use of SAE in patients treated nonoperatively reduced the failure of this method to $2-4 \%(30-33)$.

Currently, the use of SAE has led to a decrease in splenic surgery (26), the frequency of emergency interventions decreasing from $33.3 \%$ to $11.9 \%$ after the introduction of this method (34) and from $55 \%$ to $30 \%$ (28), respectively. According to Carlotto (35) AES is an independent predictive factor for splenic preservation in patients selected for NOM. However, only $5-7 \%$ of patients with splenic contusions require angioembolization (2).

The disadvantages of the method are represented by: difficult monitoring and resuscitation (in the Angiography Laboratory), the need for the presence of the interventional radiology doctor, time consuming procedure (with the risk of a possible hemodynamic decompensation of the patient), the possibility of an increased volume of CA (risk of induced nephropathy of IVCA).

Bauer (24) highlights the differences between traumatized patients and those with non-traumatic pathology requiring angiography / AE: young, blood vessels without pathological changes, smaller diameter, increased possibility of vascular spasm, more frequent hemodynamic compensation, the need for increased volume of $\mathrm{CA}$ due to increased cardiac output secondary to hypovolemia, the risk of low contrast nephropathy (even in conditions where CT with IVCA was previously performed), the presence of coagulopathy.

However, the role of SAE in severe contusive lesions (AIS $>2$; AAST grade $\geq 3$ ) is controversial (36). His study included 10,405 contusive splenic traumas in the period 20072010 (267 Level I and II Trauma Centers in the USA). Embolization of severe splenic lesions (grade IV), even in the absence of "contrast blush", increases splenic preservation (Jacksonville study, Florida-37,38). Moreover, early SAE (within the first 6 hours of hospitalization) is associated with splenic rescue.

\section{Mechanisms of Hemostasis}

They differ depending on the type of material used for embolization: temporary or permanent.

- metal spirals: they induce thrombocytosis and do not cause mechanical obstruction (16); are useful in proximal embolization and in the "sandwich" technique (isolated intrasplenic pseudoaneurysms, arteriovenous fistula);

- Gelfoam: temporary embolizing agent; released intravascularly follows the blood flow, occluding the vessel; causes thrombosis by contact with platelets by capturing them in its porous structure and accelerating thrombus development; provides structural support for the thrombus (39); arterial recanalization occurs in 2-3 weeks (16), with variations between 3 weeks-4 months) (17). Advantages: cheap, easy to prepare, temporary agent; Disadvantages: rebleeding is possible due to the fact that the particles do not have uniform dimensions (17); can cause infection / abscess by its ability to retain gas bubbles (39).

The first splenic angioembolization with Gelfoam was performed for preoperative hemostatic purposes (before a splenectomy) (18).

- Thrombin: derived from bovine thrombin (allergen risk); directly activates fibrinogen by converting it to fibrin monomers (17). It is useful in the embolization of intrasplenic pseudoaneurysms.

Most agents used for embolization require an unaffected coagulation mechanism, which requires the use of this therapeutic modality before the occurrence of coagulation disorders (17).

Large-caliber vessels are embolized with spirals and smaller ones with gelatin particles / sponge (Gelfoam; Upjohn, Kalamazoo, MI) or 
microspirals (40).

Embolization using spirals is more effective (92\%) than using Gelfoam (84\%) and severe complications are lower (20\%) for spirals vs. Gelfoam (34\%) (39).

\section{Tomographically diagnosed post-traumatic vascular lesions (MDCTangioCT) with indication for angiography}

The recent AAST guidelines - $2018(10,41)$ included splenic vascular lesions (active extravasation of the contrast agent, pseudoaneurysm, arterio-venous fistula) in the CT imaging criteria for the classification of posttraumatic lesions:

- grade IV: vascular injury or active intracapsular bleeding;

- grade V: vascular lesion or extensive extracapsular active bleeding.

The vascular lesions highlighted by this method are represented by $(16,19,24,42$, 43,44):

- extravasation of the extra- or intrasplenic contrast agent; (increased risk of SAE failure) (45); the extravasation of the intrasplenic contrast agent is represented by a persistent "blush" that appears before the venous phase and does not disappear in the parenchymal phase.

- multiple areas of extravasation of IVCA.

- PSA: intraparenchymal sacular collection delimited with a density similar to the adjacent vessels, without evidence of blood extravasation.

Omert et al. (46) considers the presence of "contrast blush" a frequent finding in severe splenic lesions, this not representing (by itself) an operative indication; is defined as an accumulation of intraparenchymal or extracapsular localized contrast material found on early or late tomographic images.

The indications for splenic angiography are $(27,33,45,47)$ :

- splenic injuries grade 3, 4, 5;

- vascular lesions found at CT initially regardless of the degree of lesion;

- active bleeding at the CT examination or "contrast blush" in the hemodynamically stable patient;

- inexplicable decrease of $\mathrm{Ht}$ in the absence of other lesions;

- large hemoperitoneum.

\section{Angiographic findings}

Conventional angiography accurately diagnoses splenic vascular lesions represented by PSA, AVF, active bleeeding, complete vascular section (23).

- located PSA;

- free extravasation of contrast agent;

- vascular lesions of terminals arteries: upper, lower, upper and lower or middle artery (complete vascular section - "cutoff"); it is highlighted angiographically as a complete vascular sectioning or a persistent arterial filling visible on late images secondary to lack of blood flow (48);

- vascular occlusion; most commonly performed by thrombus. Vascular injury can be represented by section, spasm, damage to the intima. Posttraumatic coagulopathy can prevent the formation of a new thrombus after resorption of the previous one so that a secondary hemorrhage is possible;

- intraparenchymal arterio-venous fistula;

- displacement of vascular branches secondary to the subcapsular hematoma;

- variable degree of lack of vascularization and irregularities in the accumulation of contrast substance (includes Seurat spleen $=$ small, punctiform, well-defined, localized or diffuse collections of contrast substance).

When there are discrepancies between angioCT and angiography it is important to determine whether they are secondary to stopping arterial bleeding or vasospasm (which masks the arterial lesion). The release of spasmogens (by lysis of blood clots) and the inflammatory response of the damaged vascular wall explain vasospasm (Macdonald, Dietrich cit. Liao 49).

To clarify the situation, "stimulated" 
angiography is useful (16) by administering Nitroglycerin; if doubts persist, prophylactic embolization is recommended. The presence of venous hemorrhage requires surgery.

In some patients there may be multiple sources of intrasplenic haemorrhage but, secondary to vasospasm induced by traumatic injury, these are not highlighted which may lead to post-procedural rebleeding in DSAE (50).

Liu (51) classified angiographic findings in splenic trauma into 4 groups:

- group 1: extravasation of extrasplenic IVCA;

- group 2: intraparenchymal IVCA extravasation;

- group 3: irregularities of the terminal arteries without IVCA extravasation;

- group 4: variable degrees of avascularity and irregularity in the accumulation of IVCA.

Clinically, SAE should be performed as early as possible after detection of extravasation of the contrast agent (on abdominal CT examination) and before hemodynamic deterioration occurs (47).

The current recommendations are:

- SAE should be performed within the first 60 minutes of hospitalization in hemodynamically stable patients with IVCA extravasation on CT examination;

- in 15-30 minutes after admission in the presence of a large hemoperitoneum (52).

SAE indications $(28,39,53)$ are:

- extravasation of IVCA/ blush / PSA/AVF at CT examination;

- severe splenic lesion grade (III-V);

- medium, large hemoperitoneum (defined as blood accumulation in both upper quadrants and pelvis); in patients with hemodynamic stability.

According to Schurr (54) and Bhullar $(37,38)$, the presence of "contrast blush" increases the risk of NOM failure 22-24 times.

Depending on the lesion "pattern", splenic angioembolization (SAE) $(23,55)$ can be performed:

- distal (supraselective); performs the isolation of the damaged vessel, maintains normal blood flow for an important splenic area but requires increased time for performance and special technical skills $(50,56)$. It also involves the use of a higher amount of contrast agent (risk of nephropathy) and a higher dose of irradiation (57), proportional to the difficulty of performing the procedure (58).

It is indicated in localized vascular lesions (vascular truncation, PSA, focal extravasation) $(55,59)$.

By occluding segmental branches, which are terminal arteries, the risk of segmental splenic infarction / abscess may be increased.

- proximal (trunk of the splenic artery, 2 $\mathrm{cm}$ distal from the origin of the dorsal pancreatic artery); is performed with metal spirals or absorbable hemostatic materials (Gelfoam-Pharmacia, Kalamazoo, MI; TachoSil) and causes hemostasis by decreasing arterial blood flow (deviated by collaterals) (60) and distal intra-splenic systolic pressure (on average by $40 \mathrm{mmHg}$ - 61) thus facilitating the organization of clots and healing of the lesion (55) (favorable for intrinsic coagulation - 62); prevents a delayed splenic rupture $(50,58)$.

The viability of the spleen is ensured by collateral circulation (branches of the left gastric artery, gastro-epiploic arteries, omental, pancreatic, short gastric arteries) fact demonstrated by experimental animal studies (63, Anderson cit. Zmora - 64).

In human studies, a reduction in intrasplenic pressure was found between 4758\% (Bessoud cit. Zmora - 63). Requarth (65) found after AESP a decrease in systolic pressure in the distal artery by an average of 67\% (significantly lower in patients with celiac trunk stenosis), which could explain the delayed postprocedural bleeding.

Splenic blood flow is maintained through the collateral vessels, which prevents splenic infarction, the development of splenic abscess and maintains immune function $(50,55,57$, 59,63).

Sclafani (31) considers that this procedure is compatible with maintaining splenic immune function and even if surgery is necessary, 
splenorrhaphy is facilitated. Proximal SAE is faster, technically easier, is associated with lower NOM failures and a lower incidence of postprocedural complications (abscess, splenic infarction) $(20,25,26,46,66,67)$.

Being a fast procedure it is very useful in trauma when the hemodynamic stability of the patient can change quickly and at the same time allows other procedures to be performed; reduces the radiation dose (55).

According to van der Vlies (26) and Imbrogno (57), the only disadvantage of proximal SAE is that, in the event of distal rebleeding, a possible supraselective embolization is difficult/technically impossible, and collateral embolization is necessary to perform a DSAE.

No significant differences were found regarding the effectiveness of these two techniques (68).

- Compound

The decision to perform PSAE after DSAE depends on the lesion pattern, the patient's condition, local practices and the preference of the interventionist radiologist (55). In the presence of multifocal lesions and angiographically objectified splenic ram lesion PSAE will be performed immediately after DSAE; In the case of a single lesion with angiographic correlation, only DSAE (58) is indicated, keeping PSAE for a possible rebleeding.

Explanation of this indication: some vascular lesions cannot be identified on initial angiography and may cause bleeding after the disappearance of vasospasm. However, this combined approach leads to a higher percentage of complications $(58.8 \%)$ compared to PSAE (18.2\%) or DSAE (28.7\%) (39).

Our study looked at 37 cases with SAE, 19 with PSAE and 18 with DSAE. There were a total of 32 complications after SAE $(86.48 \%$ from the group A); 15 complications after PSAE (3 major complications: 1 postprocedural bleeding- splenectomy, 1 pseudocyst, 1 splenic atrophy) and no major complications after DSAE. Globally we had $9.37 \%$ major complications and $90.62 \%$ minor complications including: fever, pleural effusion, pneumonia and partial splenic infarction. We didn't had access site complications and we didn't record any deaths. The preference of our interventional radiologists is to perform DSAE whenever possible.

The most recent studies on this topic $(38,69,70,71)$ present the following final indications of SAE:

- "contrast blush" at the initial CT examination;

- splenic lesion grade IV-V established at the initial CT examination;

- moderate hemoperitoneum;

- decrease in $\mathrm{Hb}$ values after hospitalization, during TNO (persistent hemorrhage).

The authors point out that the indication of SAE often implies the simultaneous presence of several mentioned factors. Their recommendation is to perform angioembolization in all cases of grade IV or V splenic ruptures, regardless of the presence / absence of other findings and its selective use for lesions grades I-III only if it has "contrast blush" or decreased $\mathrm{Hb}$ during NOM.

In patients with tomographic changes but with normal angiography, the indication for SAE is unclear.

Our practice is to strongly consider angiography in patients who have AAST grade III injury associated with medium or large hemoperitoneum.

In patients at high risk it is indicated prophylactic PSAE $(50,61,72,73)$ with the following indications:

- over the age of 50;

- large hemoperitoneum;

- polytraumatized;

- which requires prolonged surgical procedures in other regions (orthopedic, neurosurgical) that increase the risk of hemorrhage and secondary aggravation of injuries (especially brain).

According to Thony (72), prophylactic splenic embolization in severe lesions without CT signs of bleeding is a specific indication for this organ.

Prophylactic embolization reduces the frequency of splenectomy by $16 \%-18 \%(27,28)$.

The limitations of this study are represented 
by: it is a retrospective analysis, there was no randomization of patients, the lack of a therapeutic protocol (which determined the inconsistent performance of the procedures) and the sample size of both study groups is still small.

Emergency Hospital Bucharest represents a landmark in traumatology in Romania, the purpose of its existence being represented by solving surgical emergencies.

The first case of splenic angioembolization (for trauma) in Romania was performed in Emergency Hospital Bucharest in 2010 (74), followed by another priority of our Institution, the first SAE of a grade IV blunt splenic trauma (75). Curently we perform splenic angioembolizations in grade V injuries as well.

\section{Conclusions}

Transcatheter splenic artery embolization has a major role in the management of traumatic splenic injuries. Splenic angioembolization should be strongly considered as an adjunct to NOM in patients with AAST Grade III-V blunt splenic injuries and in Grades I and II only in the cases with splenic vascular lesions or a large hemoperitoneum. Our results reveal a crossover from splenectomy to SAE, as a primary treatment modality for blunt splenic injuries. In our institution SAE remains a mainstay in the treatment of patients suffering blunt trauma to the spleen.

\section{Conflict of Interest}

The authors declare no conflicts of interest.

\section{Ethical Statement}

The authors are responsible for all aspects of this study; all the aspects previously mentioned by the reviewers had been analized and clarified.

\section{Authors' Contributions}

DPV, MB, LG and MP contributed to the creation and accomplishment of this study: DPV wrote the article. DPV and MB have coordinated, analyzed, collected th data and organized the literary medical review. MDV, CO, CM, GP, TGT collected the data, supervized the study and participated into writing and improvement of this research.

\section{References}

1. Moore FA, Davis JW, Moore EE, Cocanour CS, West MA, McIntyre RC Jr. Western trauma association (WTA) critical decisions in trauma: management of adult blunt splenic injury. J Trauma. 2008;65:1007-11.

2. Stassen NA, Bhullar I, Cheng JD, Crandall ML, Friese RS, Guillamondegui OD, et al. Selective nonoperative management of blunt splenic injury: an Eastern Association for the Surgery of Trauma practice management guideline. J Trauma Acute Care Surg. 2012;73(5 Suppl 4):S294-300.

3. Beuran M, Gheju I, Venter MD, Marian RC, Smarandache R. Non-operative management of splenic trauma. J Med Life. 2012;5(1):47-58.

4. Yiannoullou P, Hall C, Newton K, Pearce L, Bouamra O, Jenks T, et al. A review of the management of blunt splenic trauma in England and Wales: have regional trauma networks influenced management strategies and outcomes? Ann R Coll Surg Engl. 2017; 99(1):63-69.

5. Fodor M, Primavesi F, Morell-Hofert D, Haselbacher M, Braunwarth E, Cardini B, et al. Non-operative management of blunt hepatic and splenic injuries-practical aspects and value of radiological scoring systems. Eur. Surg. 2018;50: 285-298.

6. Smith SR, Morris L, Spreadborough S, Al-Obaydi W, D'Auria M, White H, et al. Management of blunt splenic injury in a UK major trauma centre and predicting the failure of non-operative management: a retrospective, crosssectional study. Eur J Trauma Emerg Surg. 2018;44(3):397-406.

7. Ruscelli P, Gemini A, Rimini M, Santella S, Candelari R, Rosati M, et al. The role of grade of injury in non-operative management of blunt hepatic and splenic trauma: Case series from a multicenter experience. Medicine (Baltimore). 2019;98(35):e16746.

8. Habash M, Ceballos D, Gunn AJ. Splenic Artery Embolization for Patients with High-Grade Splenic Trauma: Indications, Techniques, and Clinical Outcomes. Semin Intervent Radiol. 2021;38(1):105-112.

9. Moore EE, Cogbill TH, Jurkovich GJ, Shackford SR, Malangoni MA, Champion HR. Organ injury scaling: spleen and liver (1994 revision). J Trauma. 1995;38(3):323-324

10. Kozar RA, Crandall M, Shanmuganathan K, Zarzaur B, Coburn M, Cribari C, et al. Organ injury scaling 2018 update: Spleen, liver, and kidney [published correction appears in J Trauma Acute Care Surg. 2019;87(2):512]. J Trauma Acute Care Surg. 2018;85(6):1119-1122.

11. Federle MP, Crass RA, Jeffrey RB, Trunkey DD. Computed tomography in blunt abdominal trauma. Arch Surg. 1982;117(5):645-50.

12. Federle MP, Jeffrey RB Jr. Hemoperitoneum studied by computed tomography. Radiology. 1983;148(1):187-92.

13. Hagiwara A, Murata A, Matsuda T, Matsuda H, Shimazaki S. The efficacy and limitations of transarterial embolization for severe hepatic injury. J Trauma. 2002;52(6):1091-6

14. Hagiwara A, Fukushima H, Murata A, Matsuda H, Shimazaki S. Blunt splenic injury: usefulness of transcatheter arterial embolization in patients with a transient response to fluid resuscitation. Radiology. 2005:235(1):57-64.

15. Fehr A, Beveridge J, D`Amours SD, Kirkpatrick AW, Ball CG. The potential benefit of a hybrid operating environment among severely injured patients with persistent hemorrhage: How often could we get it right? J Trauma Acute Care Surg. 2016;80(3):457-60.

16. Salsamendi J, Quintana D, Kably I, Narayanan G. Special considerations for embolization in trauma cases. Clinical indicators and arterial embolization techniques. Endovascular Today. 2013:12(4):42-49.

17. Lopera JE. Embolization in trauma: principles and techniques. Semin Intervent Radiol. 2010;27(1):14-28.

18. Sclafani SJ. The role of angiographic hemostasis in salvage of the injured spleen. Radiology. 1981;141(3):645-50. 
19. Pryor JP, Braslow B, Reilly PM, Gullamondegi O, Hedrick JH, Schwab CW. The evolving role of interventional radiology in trauma care. J Trauma. 2005; 59(1):102-4.

20. Smith HE, Biffl WL, Majercik SD, Jednacz J, Lambiase R, Cioffi WG. Splenic artery embolization: Have we gone too far? J Trauma. 2006;61(3):541-4; discussion 545-6.

21. Wei B, Hemmila MR, Arbabi S, Taheri PA, Wahl WL. Angioembolization reduces operative intervention for blunt splenic injury. J Trauma. 2008; 64(6):1472-7.

22. Dehli T, Btgenholm A, Trasti NC, Monsen SA, Bartnes K. The treatment of spleen injuries: a retrospective study. Scand J Trauma Resusc Emerg Med. 2015. 29;23:85

23. Patil MS, Goodin SZ, Findeiss LK. Update: Splenic Artery Embolization in Blunt Abdominal Trauma. Semin Intervent Radiol. 2020;37(1):97-102.

24. Bauer JR, Ray CE. Transcatheter arterial embolization in the trauma patient: a review. Semin Intervent Radiol. 2004;21(1):11-22.

25. van der Vlies $\mathrm{CH}$, van Delden OM, Punt BJ, Ponsen KJ, Reekers JA, Goslings JC. Literature review of the role of ultrasound, computed tomography, and transcatheter arterial embolization for the treatment of traumatic splenic injuries. Cardiovasc Intervent Radiol. 2010;33(6):1079-87.

26. van der Vlies CH, Hoekstra J, Ponsen KJ, Reekers JA, van Delden OM, Goslings JC. Impact of splenic artery embolization on the success rate of nonoperative management for blunt splenic injury. Cardiovasc Intervent Radiol. 2012;35(1):76-81.

27. Haan JM, Bochicchio GV, Kramer N, Scalea TM. Nonoperative management of blunt splenic injury: a 5-year experience. J Trauma. 2005;58(3):492-8.

28. Gaarder C, Dormagen JB, Eken T, Skaga NO, Klow NE, Pillgram-Larsen J, et al. Nonoperative management of splenic injuries: improved results with angioembolization. J Trauma. 2006;61(1):192-8.

29. Frandon J, Rodiere M, Arvieux C, Michoud M, Vendrell A, Broux C, et al. Blunt splenic injury: are early adverse events related to trauma, nonoperative management, or surgery? Diagn Interv Radiol. 2015;21(4):327-333.

30. Sclafani SJ, Weisberg A, Scalea TM, Phillips TF, Duncan AO. Blunt splenic injuries: nonsurgical treatment with CT, arteriography, and transcatheter arterial embolization of the splenic artery. Radiology. 1991;181(1):189-96.

31. Sclafani SJ, Shaftan GW, Scalea TM, Patterson LA, Kohl L, Kantor A, et al. Nonoperative salvage of computed tomography-diagnosed splenic injuries: utilization of angiography for triage and embolization for hemostasis. J Trauma. 1995:39(5):818-25; discussion 826-7.

32. Haan J, Scott J, Boyd-Kranis RL, Ho S, Kramer M, Scalea TM. Admission angiography for blunt splenic injury: advantages and pitfalls. J Trauma. 2001;51(6):1161-5.

33. Dent D, Alsabrook G, Erickson BA, Myers J, Wholey M, Stewart R, et al. Blunt splenic injuries: high nonoperative management rate can be achieved with selective embolization. J Trauma. 2004:56(5):1063-7.

34. Renzulli P, Gross T, Schnüriger B, Schoepfer AM, Inderbitzin D, Exadaktylos AK et al. Management of blunt injuries to the spleen. Br J Surg. 2010; 97(11) 1696-703.

35. Carlotto JR, Lopes-Filho Gde J, Colleoni-Neto R. Main Controversies in the Nonoperative Management of Blunt Splenic Injuries. Arq Bras Cir Dig. 2016; 29(1):60-4

36. Zarzaur BL, Savage SA, Croce MA, Fabian TC. Trauma center angiography use in high-grade blunt splenic injuries: Timing is everything. Journal of Trauma and Acute Care Surgery. 2014;77(5):666-673.

37. Bhullar IS, Frykberg ER, Siragusa D, Chesire D, Paul J, Tepas JJ 3rd, Kerwin AJ. Selective angiographic embolization of blunt splenic traumatic injuries in adults decreases failure rate of nonoperative management. J Trauma Acute Care Surg. 2012;72(5):1127-34

38. Bhullar IS, Tepas JJ III, Siragusa D, Loper T, Kerwin A, Frykberg ER. To nearly come full circle: Nonoperative management of high-grade IV-V blunt splenic trauma is safe using a protocol with routine angioembolization. Journal of Trauma and Acute Care Surgery. 2017;82:657-664.

39. Rong JJ, Liu D, Liang M, Wang QH, Sun JY, Zhang QY, et al. The impacts of different embolization techniques on splenic artery embolization for blunt splenic injury: a systematic review and meta-analysis. Mil Med Res. 2017 30;4:17.

40. Alarhayem AQ, Myers JG, Dent D, Lamus D, Lopera J, Liao L, et al. "Blush at first sight": significance of computed tomographic and angiographic discrepancy in patients with blunt abdominal trauma. Am J Surg. 2015; 210(6):1104-1111.

41. Organ injury scaling 2018 update: Spleen, liver, and kidney: Erratum. J Trauma Acute Care Surg. 2019;87(2):512. Erratum for: J Trauma Acute Care Surg. 2018;85(6):1119-1122

42. Ruhnke H, Jehs B, Schwarz F, Haerting M, Rippel K, Wudy R, et al. Non-operative management of blunt splenic trauma: The role of splenic artery embolization depending on the severity of parenchymal injury. Eur $\mathrm{J}$ Radiol. 2021;137:109578. Epub 2021 Feb 4.

43. Haan J, Ilahi ON, Kramer M, Scalea TM, Myers J. Protocol-driven nonoperative management in patients with blunt splenic trauma and minimal associated injury decreases length of stay. J Trauma. 2003;55(2):317-21; discussion 321-2.

44. Cooney R, Ku J, Cherry R, Maish GO 3rd, Carney D, Scorza LB, Smith JS. Limitations of splenic angioembolization in treating blunt splenic injury. J Trauma. 2005;59(4):926-32; discussion 932.

45. Sabe AA, Claridge JA, Rosenblum DI, Lie K, Malangoni MA. The effects of splenic artery embolization on nonoperative management of blunt splenic injury: a 16-year experience. J Trauma. 2009;67(3):565-72; discussion 571-2.

46. Omert LA, Salyer D, Dunham CM, Porter J, Silva A, Protetch J. Implications of the "contrast blush" finding on computed tomographic scan of the spleen in trauma. J Trauma. 2001;51(2):272-7; discussion 277-8.

47. Wu SC, Chow KC, Lee KH, Tung CC, Yang AD, Lo CJ. Early selective angioembolization improves success of nonoperative management of blunt splenic injury. Am Surg. 2007;73(9):897-902.

48. Atluri S, Richard HM 3rd, Shanmuganathan K. Optimizing multidetector CT for visualization of splenic vascular injury. Validation by splenic arteriography in blunt abdominal trauma patients. Emerg Radiol. 2011;18(4): 307-12.

49. Liao CA, Kuo LW, Wu YT, Liao CH, Cheng CT, Wang SY, et al. Unstable Hemodynamics is not Always Predictive of Failed Nonoperative Management in Blunt Splenic Injury. World J Surg. 2020;44(9):2985-2992.

50. Hoppe H, Kos S. Splenic Artery Embolization: Proximal or Distal? A review of when proximal or distal embolization should be used, optimal technique, and results of studies evaluating outcomes. Endovascular Today. 2018; 17(4):73-76

51. Liu PP, Lee WC, Cheng YF, Hsieh PM, Hsieh YM, Tan BL, et al. Use of splenic artery embolization as an adjunct to nonsurgical management of blunt splenic injury. J Trauma. 2004;56(4):768-72; discussion 773.

52. Van der Cruyssen F, Manzelli A. Splenic artery embolization: technically feasible but not necessarily advantageous. World Journal of Emergency Surgery. 2016. 11(1):47

53. Fu CY, Wu SC, Chen RJ, Chen YF, Wang YC, Huang HC, et al. Evaluation of need for operative intervention in blunt splenic injury: intraperitoneal contrast extravasation has an increased probability of requiring operative intervention. World J Surg. 2010;34(11):2745-51

54. Schurr MJ, Fabian TC, Gavant M, Croce MA, Kudsk KA, Minard G, et al. Management of blunt splenic trauma: computed tomographic contrast blush predicts failure of nonoperative management. J Trauma. 1995;39(3):507-12; discussion 512-3

55. Quencer KB, Smith TA. Review of proximal splenic artery embolization in blunt abdominal trauma. CVIR Endovasc. 2019;2(1):11.

56. Harbrecht BG. Is anything new in adult blunt splenic trauma? Am J Surg. 2005;190(2):273-8.

57. Imbrogno BF, Ray CE. Splenic artery embolization in blunt trauma. Semin Intervent Radiol. 2012;29(2):147-9.

58. McCabe S, Maddineni S, Marini C, Rozenblit G. Vascular and interventional radiology in blunt abdominopelvic trauma - Institutional practice and review of the literature. J. Trauma Treat. 2016:5:324.

59. Bessoud B, Denys A. Main splenic artery embolization using coils in blunt splenic injuries: effects on the intrasplenic blood pressure. Eur Radiol. 2004;14(9):1718-9.

60. Yip H, Skelley A, Morphett L, Mathew J, Clements W. The cost to perform splenic artery embolisation following blunt trauma: Analysis from a level 1 Australian trauma centre. Injury. 2020:S0020-1383(20)30737-3.

61. Thony F. Embolization for splenic trauma. Healing the spleen with curative and 
preventive embolization. Endovascular Today. 2016;15(4):72-91.

62. Preece SR, Schriber SM, Choudhury KR, Suhocki PV, Smith TP, Kim CY. Coil embolization of the splenic artery: impact on splenic volume. J Vasc Interv Radiol. 2014;25(6):859-865.

63. Zmora 0, Kori Y, Samuels D, Kessler A, Schulman Cl, Klausner JM, et al. Proximal Splenic Artery Embolization In Blunt Splenic Trauma. Eur J Trauma Emerg Surg. 2009;35(2):108.

64. Hagiwara A, Yukioka T, Ohta S, Nitatori T, Matsuda H, Shimazaki S. Nonsurgica management of patients with blunt splenic injury: efficacy of transcatheter arterial embolization. AJR Am J Roentgenol. 1996;167(1):159-66.

65. Requarth JA, Miller PR. The splenic artery stump pressure is affected by arterial anatomy after proximal embolotherapy in blunt splenic injury. J Trauma Acute Care Surg. 2012;73(5):1221-4.

66. Killeen KL, Shanmuganathan K, Boyd-Kranis R, Scalea TM, Mirvis SE. CT findings after embolization for blunt splenic trauma. J Vasc Interv Radiol. 2001; 12(2):209-14

67. Haan JM, Marmery H, Shanmuganathan K, Mirvis SE, Scalea TM. Experience with splenic main coil embolization and significance of new or persistent pseudoaneurym: reembolize, operate, or observe. J Trauma. 2007;63(3):615-9

68. Rasuli P, Moosavi B, French GJ, Petrcich W, Hammond I. Splenic Artery Embolization in Blunt Trauma: A Single-Center Retrospective Comparison of the Use of Gelatin Sponge Versus Coils. AJR Am J Roentgenol. 2017; 209(6): W382-W387.
69. Martin JT, Hulsberg PC, Soule E, Shabandi M, Matteo J. Welcome to the new era: a completely wireless interventional procedure. Cureus. 2018, 10:e3337: 10.7759/cureus.3337.

70. Alamri Y, Moon D, Yen DA, Wakeman C, Eglinton T, Frizelle F. Ten-year experience of splenic trauma in New Zealand: the rise of non-operative management. N Z Med J. 2017;130(1463):11-18.

71. Crichton JCl, Naidoo K, Yet B, Brundage SI, Perkins Z. The role of splenic angioembolization as an adjunct to nonoperative management of blunt splenic injuries: A systematic review and meta-analysis. J Trauma Acute Care Surg. 2017;83(5):934-943

72. Thony F, Rodière M, Frandon J, Vendrell A, Jankowski A, Ghelfi J, Set al. Polytraumatism and solid organ bleeding syndrome: The role of imaging. Diagn Interv Imaging. 2015;96(7-8):707-15.

73. Arvieux C, Frandon J, Tidadini F, Monnin-Bares V, Foote A, Dubuisson V, et al. Effect of Prophylactic Embolization on Patients With Blunt Trauma at High Risk of Splenectomy: A Randomized Clinical Trial. JAMA Surg. 2020; 155(12):1102-1111.

74. Venter MD, Marian RC, Palea M, Ungureanu A, Morteanu S, Gulie L, et al. Splenic angioembolization--a safe, efficient and rational approach. Chirurgia (Bucur). 2010;105(2):243-8. Romanian.

75. Gheju I, Venter MD, Beuran M, Gulie L, Racoveanu I, Carstea P, Iftimie Nastase I, Venter DP. Grade IV blunt splenic injury--the role of proximal angioembolization. A case report and review of literature. J Med Life. 2013;6(4):369-75. 